\title{
Educação Infantil e Práticas Pedagógicas para o Aluno com Síndrome De Down: o Enfoque no DesenVolvimento Motor ${ }^{1}$ Teaching Practices for Students With Down Syndrome and Childhood EDUCATION: A FOCUS ON MOTOR DEVELOPMENT
}

\author{
Lívia Maria Ribeiro Leme ANUNCIAÇÃO ${ }^{2}$ \\ Maria Piedade Resende da COSTA ${ }^{3}$ \\ Fátima Elisabeth DENARI ${ }^{4}$
}

\begin{abstract}
RESUMO: a presente pesquisa tem como objetivos: identificar qual o nível de desenvolvimento motor de uma criança com Síndrome de Down (SD) no contexto educacional, intervir com estratégias de ensino necessárias para responder às necessidades de seu desenvolvimento e avaliar os avanços no seu desenvolvimento após a intervenção. O método utilizado foi o estudo de caso para analisar o fenômeno em seu contexto real. Como participante foi escolhido um aluno com SD de três anos de idade matriculado em uma escola de educação infantil de uma cidade de médio porte do interior do estado de Sáo Paulo. O procedimento para a coleta de dados foi realizado em três etapas: 1) pré-teste, 2) intervenção e 3) pós-teste. Na fase do pré-teste foi aplicado o Inventário Portage Operacionalizado na área de desenvolvimento motor. Ao identificar as necessidades de aprendizagem do aluno foi elaborado e aplicado um plano de intervenção. Depois da etapa de intervenção, no pós-teste, o inventário foi novamente aplicado para mensurar os avanços no desenvolvimento do aluno comparando-o com o pré-teste. Como resultado constatou-se que o aluno avançou em relaçáo à faixa etária inicial referente ao período de um a dois anos para a idade entre dois a três anos em seu desenvolvimento.
\end{abstract}

PALAVRAS-CHAVE: Educação Especial. Síndrome de Down. Educação Infantil. Desenvolvimento Motor.

\begin{abstract}
This study aims to: identify the motor development level of a child with Down Syndrome (DS) in the educational context, intervene with teaching strategies necessary to meet the needs of their development and assess progress in development after intervention. The method used was the case study in order to examine the phenomenon in its real context. The research participant was a three year old nursery school student with Down Syndrome from a medium sized city in the state of São Paulo. The procedure for data collection was conducted in three stages: pre-test, intervention and post-test. At the pre-test stage the Operational Portage was applied to assess the motor development area. After identifying the learning needs of student an action plan related to the school routine was developed and implemented. After the intervention phase, at the post-test phase, the inventory was again used to measure the progress in the student's development by comparing it to the pre-test. As a result it was found that the student had advanced in relation to the initial age group of one to two years to the age of two to three years in his development.
\end{abstract}

KEYWORDS: Special Education. Down syndrome. Early Childhood Education. Motor Development.

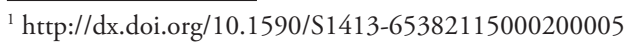

${ }^{2}$ Doutoranda em Educação Especial pela Universidade Federal de São Carlos. Docente Centro de Ciências Humanas da Universidade do Sagrado Coração - USC. Bauru, SP, Brasil. livia.maleme@gmail.com

${ }^{3}$ Departamento de Psicologia da Universidade Federal de São Carlos, Programa de Pós-Graduação em Educação Especial da UFSCar, São Carlos, SP, Brasil. piedade@ufscar.br

${ }^{4}$ Departamento de Psicologia da Universidade Federal de São Carlos, Programa de Pós-Graduação em Educação Especial da UFSCar, São Carlos, SP, Brasil. fadenari@terra.com.br
} 


\section{INTRODUÇÁo}

As políticas públicas e a legislação em educação inclusiva promovem e garantem o acesso ao ensino básico de alunos em condição de deficiência. A Educação Básica constitui-se da Educação Infantil, Ensino Fundamental e Ensino Médio. Ao se designar a Educação Especial como modalidade que complementa a Educação Básica subentende-se que tal modalidade também encontra espaço para trabalhos pedagógicos na Educação Infantil (BRASIL, 2001).

Assim, nas Diretrizes Curriculares Nacionais para a Educação Infantil a criança com deficiência só é mencionada no item de organização do espaço, tempo e material ao se expor a importância da acessibilidade. Além de reconhecer a valorizaçáo da diversidade e propor o combate à discriminaçấo (BRASIL, 2010).

O ensino especial na Educação Infantil necessita de mais estudos para que essa prática se consolide para favorecer situaçôes reais de aprendizagem. Para Leme (2010, p.47) “[...] pensar em dificuldades sem pensar em soluçóes é como não acreditar que a Educação possa ser transformadora de uma forma realista”.

Particularmente, o aluno com Síndrome de Down (SD) faz parte desse alunado. Dissertar sobre a SD é rotineiro nos estudos acadêmicos. Reflexóes e proposições sobre essa síndrome somam a cada estudo/pesquisa uma diversidade de olhares para a pessoa com deficiência, dentre as áreas de humanas, biológicas, exatas e entre outras.

Atualmente, com a porta de entrada para a escolarização do aluno com deficiência no ensino regular que institui o atendimento educacional especializado e a Educação Especial como modalidade de ensino, a criança com SD inicia sua caminhada logo na educaçáo infantil (BRASIL, 1988, 1996).

Conforme o exposto alguns questionamentos surgem, tais como: quais sáo os desafios do processo inicial de escolarização de uma criança com SD em seu primeiro ano escolar? Quais estratégias são necessárias para se identificar suas necessidades reais de aprendizagem?

Para isso, o estado da arte responde a diversas questôes que serão apresentadas a seguir.

A literatura na área de humanas, ainda precisa de enfoque em pesquisas para se conhecer e criar práticas pedagógicas coerentes com as necessidades de aprendizagem dos alunos com SD. O mesmo aspecto foi identificado por Faria (1993) há mais de 20 anos que mostra que as pesquisas com essa população ocorrem mais na área médica do que na educacional.

Em se tratando de pesquisas com SD, são apresentadas no estudo de Comin (2013) um levantamento de teses e dissertaçóes entre os anos de 2001 e 2011 utilizando o descritor "Síndrome de Down". A pesquisa mostra que nesse período foram desenvolvidos 436 trabalhos com essa temática. Dentre esse universo 106 são da área de humanas. O restante distribui-se entre biológicas, exatas e áreas indefinidas com maior número de trabalhos. No mesmo estudo a pesquisadora realizou um levantamento de artigos nacionais e internacionais. As bases de dados pesquisadas foram Scielo, Portal Capes e Google Acadêmico. Dentre os artigos nacionais foram encontrados 145 artigos no Scielo e 4575 no Google Acadêmico. A pesquisa na base de dados internacional apresentou 73 artigos no portal Capes e 16723 no Google Acadêmico. Na área de humanas apenas seis artigos nacionais e cinco internacionais. 
Identifica-se a necessidade de programas de ensino e pesquisas eficazes para que a inclusão seja capaz de proporcionar aos alunos com SD momentos de aprendizagem que respondam às suas necessidades e divulgação de tais resultados na área de humanas. Perrenoud (2010) relata, sob o ponto de vista da diversidade humana, que todas as crianças precisam obter no processo de escolarização situaçóes fecundas de aprendizagem. Para isso, os sistemas de ensino deverão assegurar aos educandos programas de ensino que garantam a permanência no ensino regular e que atenda ao princípio da qualidade de ensino. No mesmo sentido, Carvalho (2010) diz que o ambiente escolar precisa remover duas barreiras, as visíveis e as invisíveis. Dentre as barreiras visíveis encontramos as pedagógicas e arquitetônicas. Já entre as invisíveis a discriminação, o preconceito e o estigma.

Um dos fatores invisíveis, conforme Carvalho (2010) foi abordado no estudo de Teixeira e Kubo (2008). A inclusão escolar da criança com SD na rede regular de ensino adquire potencial significativo para seu desenvolvimento, entretanto existe uma visão negativa sobre esses potenciais. Diante disso, as pesquisadoras, realizaram um estudo para identificar as percepçóes de alunos sem deficiência sobre as interações com crianças SD no ensino regular. As pesquisadoras elaboraram um questionário estruturado em que os participantes deveriam indicar um amigo, não amigo e um colega que fará faculdade. No estudo "[...] foi constatado que quanto maior o desenvolvimento acadêmico e o grau de participação nas atividades escolares, maior será a possibilidade do aluno com a síndrome ser considerado amigo por seus colegas" (TEIXEIRA; KUBO, 2008, p.75). Assim, dentre as categorias investigadas os alunos com SD foram os que receberam menores indicaçóes.

Identifica-se então que o aluno com SD, quando em um ambiente escolar, não possui efetiva participação nas atividades pedagógicas. $\mathrm{O}$ estudo remete à reflexão de quais são os maiores desafios da inclusão e quais são os fatores que levam a criança com SD ter baixos índices de aceitação pelos colegas, além de obter índices insatisfatórios de aprendizagem.

Nesse sentido, Rosa e Luiz et al. (2008) apontam que os fatores que dificultam o processo de inclusão do SD na rede de ensino regular relacionam-se à escola, à família e ao professor.

Portanto os desafios que as crianças com SD encontram precisam ser apresentados e abordados para que a inclusão seja satisfatória do ponto de vista de que todas as crianças podem aprender e ter a possibilidade de manter um nível aceitável de aprendizagem. Os sistemas de ensino, enfim, devem manter e assegurar programas de ensino considerando a vasta diversidade educacional (UNESCO, 1994).

O dinamismo da sala de aula transporta uma multiplicidade de pensamentos, vivências e necessidades educacionais específicas.

Dentre as necessidades pedagógicas o enfoque da presente pesquisa está relacionado a temas que permeiam o desenvolvimento motor de pessoas com SD.

Faria (1993, p.10) há mais de 20 anos apontava no seu estudo o mito que as crianças com SD eram "[...] consideradas incapazes de desenvolver as menores habilidades, cuidados pessoais e socialização". Entretanto, vale salientar que nos achados do seu estudo os alunos com SD necessitam de um tempo maior para aprendizagem que esse processo deve promover a autonomia e independência dos alunos (FARIA, 1993). 
Seguindo o Método Montessori de ensino Lamoréa (1995) promoveu uma investigação com crianças SD na faixa etária entre três e sete anos. No estudo cada criança obteve êxito conforme seu ritmo e repertório no decorrer do processo.

Os processos de escolarização de crianças com SD ocorrem nas diversas salas de aula existentes pelo Brasil. Dentre as diversas características das pessoas com SD estão a dificuldade de coordenação motora e atraso no nível intelectual e motor. Para fundamentar a presente pesquisa serão apresentados a seguir estudos que permeiam e buscam respostas aos aspectos de seu desenvolvimento motor.

Campos, Coelho e Rocha (2010) ao avaliar o desempenho motor e sensorial de lactentes (seis meses de idade) com e sem síndrome de Down, indica que as crianças com SD possuem desenvolvimento motor inferior quando comparados aos típicos.

Santos, Weiss e Almeida (2010) mostram através de uma pesquisa descritiva com uma criança de sete anos com SD que, ao analisar seu desenvolvimento na motricidade global e fina, que essa área necessita de mais programas de intervenção para estimulação de crianças com essa síndrome. No estudo a criança, depois de passar por testes e intervençóes, apresentou dificuldade na linguagem, déficit motor e motricidade fina. Entretanto, após as intervençóes ocorreu avanço nas áreas de motricidade global, equilíbrio e organização espacial. $\mathrm{O}$ estudo apresentado demonstra que é possível se atingir significativo progresso no desenvolvimento da pessoa com SD, além de inferir que as áreas que mais precisam de atenção são linguagem, esquema corporal e a motricidade fina. Com o estudo, ao focar as aptidóes motoras, os pesquisadores apontam que "[...] eleva-se a importância do desenvolvimento motor durante a infância, considerando também que o acompanhamento da aptidão motora de crianças em idade escolar constitui atitude preventiva quanto à aprendizagem" (SANTOS; WEISS; ALMEIDA, 2010, p.20). Estima-se, portanto a necessidade de programas de intervenção para essa população.

O estudo apresentado resulta em dados importantes relacionados ao desenvolvimento motor ao relacioná-lo com a aquisição da aprendizagem. Com isso, quando criados momentos de estimulação precoce das habilidades motoras em crianças em idade escolar pode-se adquirir avanços nos aspectos relacionados à aprendizagem.

Na pesquisa de Corrêa et al. (2011), com o objetivo de analisar e verificar a existência de alteraçóes neurofisiológicas em pessoas com SD, a falta e atraso do desenvolvimento motor pode ocasionar prejuízo no controle motor levando a hipotonia. Como característica própria da síndrome, o estudo mostra que "a hipotonia e fraqueza muscular [...] vêm sendo sugeridos como causa do atraso no desenvolvimento motor para as crianças do SD” (p. 20). Tais aspectos podem interferir nas atividades funcionais das crianças ao longo da vida.

Brito et al. (2009) desenvolveram um estudo, utilizando o Inventário Portage (WILLIANS; AIELLO, 2001) como instrumento. Participaram 20 crianças SD para avaliar seu perfil cinestésico-corporal e assim estabelecer parâmetros cognitivo-motores para fundamentar "[...] práticas heterogêneas no projeto político pedagógico, no currículo, na metodologia de ensino e na avaliação voltadas para a inclusão social de qualquer criança com necessidades educacionais especiais" (p.351). 
Os resultados do estudo mostram que as crianças apresentaram dificuldade em realizar tarefas de coordenação motora fina. Outro dado importante apresentado no estudo se refere à hipotonia periférica ou central apresentada, associada ao déficit da coordenação motora fina. Isso gera limitaçóes na linguagem (oral e escrita) que resulta insucessos em atividades acadêmicas. Por isso, de acordo com os autores, vale ressaltar a necessidade de realizar uma avaliação individual de cada indivíduo para traçar seu perfil e planejar uma intervenção pedagógica significativa (BRITO et al., 2009).

Segundo Serés et al. (2011, p.141), para crianças com SD a hipotonia é uma das causas do atrasado da aquisição das habilidades motoras. Complementam o conceito sobre a hipotonia com a seguinte explicação:

O tônus muscular é a contração parcial, passiva e contínua dos músculos. Ajuda a manter a postura de forma involuntária, não dependendo da força muscular, e sim da capacidade de regular a contração dos músculos de forma equilibrada. Quando o tônus muscular diminui há o que é conhecido como hipotonia.

É importante programas de estimulação com atividades que potencializam o desenvolvimento motor sendo elas lúdicas e atrativas para a criança. Os autores inferem que tais atividades proporcionam e facilitam o desenvolvimento de reaçóes de equilíbrio e aquisição de certas posturas.

Os estudos apresentados mostram a indicação de que as pessoas com síndrome de Down possuem atraso no desenvolvimento motor. Assim, os dados mostram que quando existem intervençóes e programas de estimulação precoce tais dificuldades são vencidas como é apresentado no estudo de Silva e Ferreira (2001). O objetivo foi verificar o nível de coordenação motora de nove crianças com SD. No pré-teste apresentavam nível baixo de desenvolvimento motor, em seguida após passar pela intervenção, no pós-teste, apresentaram melhoras nas respostas motoras.

As pesquisas sobre inclusão na Educação Infantil de crianças com SD são escassas e precisam ser amplamente divulgadas para aumentar a divulgação de procedimentos de ensino que promovam reflexóes nos diversos contextos em que esse público estiver presente.

O currículo da Educação Infantil é pautado no Referencial Curricular Nacional (RCNEI) (BRASIL, 1998). As áreas do conhecimento que a Educação Infantil contempla são: música, natureza e sociedade, matemática, linguagem oral e escrita, artes e movimento tendo o brincar e a ludicidade como fundamentos. No documento, para cada área do conhecimento, são elencados objetivos e conteúdo para a faixa etária de zero a três anos.

Ao se falar em ludicidade e brincadeiras, tanto Serés et al. (2011) ao mencionar a importância de se trabalhar com propostas lúdicas para diminuir a hipotonia em crianças com SD, Boccardi (2003) mostra em seu estudo utilizando-se de um programa de intervenção motora lúdica inclusiva que o brincar, nas atividades propostas, proporciona, além de satisfazer as necessidades infantis, novos referenciais motores.

Alvo de estudos na área de Educação Especial o currículo pode/deve passar por ajustes para se atender às necessidades de aprendizagem dos alunos. Fonseca (2011) afirma que 
existe a necessidade de práticas pedagógicas variadas na classe comum, pois é esse o local onde deve ser devolvido o currículo para o aluno com deficiência para responder adequadamente às suas condiçóes e características.

Embora exista um Referencial Curricular Nacional para a Educação Infantil, o mesmo não atende às necessidades de crianças com deficiência. Para contemplar tais peculiaridades existe a possibilidade de ajustes curriculares.

Diante do exposto, as questóes norteadoras do presente estudo foram: 1) será possível o avanço no desenvolvimento acadêmico de uma criança de três anos com SD no processo inicial de inclusão na Educaçáo Infantil, e 2) será que a permanência da criança com SD no ensino infantil atende aos objetivos propostos para a faixa etária?

Para responder as questóes, a presente pesquisa teve como objetivos: 2) identificar qual o nível de desenvolvimento motor de uma criança com Síndrome de Down (SD) no contexto educacional, 2) intervir com estratégias de ensino necessárias para responder às necessidades de seu desenvolvimento e, 3) avaliar os avanços no seu desenvolvimento após a intervenção

\section{Método}

$\mathrm{Na}$ caracterização da pesquisa, para atender ao objetivo, o método utilizado foi o estudo de caso.

O estudo de caso, de acordo com Yin (2001), estuda o fenômeno dentro de seu contexto real. Partindo dessa premissa a escolha do estudo de caso responde ao objetivo proposto da pesquisa. Outro aspecto importante do estudo de caso que será encontrado no trabalho identifica-se com o pensamento de Vilelas (2009) que a forma descritiva da realidade e condição se procura conhecer as características da população e/ou fenômeno, relacionando-os e aumentando o conhecimento sobre o problema estudado.

Diante do exposto o método condiz com os objetivos propostos, pois será estudado o fenômeno em si e ocorrerá a relação em seu contexto real.

Participou da presente pesquisa um aluno SD com idade entre três e quatro anos de idade cronológica no processo inicial de escolarização. A mãe do aluno foi colaboradora do estudo quanto às informaçóes sobre o desenvolvimento do aluno de acordo com os itens do Inventário Portage Operacionalizado (WILLIANS; AIELLO, 2001)

A pesquisa foi realizada em uma escola de Educação Infantil de uma cidade de médio porte do interior do estado de São Paulo

\subsection{InSTRUMENTO PARA COLETA DE DADOS}

Para a coleta de dados sobre o nível de desenvolvimento motor do participante foi utilizado o Inventário Portage Operacionalizado (WILLIAMS; AIELLO, 2001). Ainda, para o registro pós-facto dos comportamentos observados foi utilizado o dicionário de campo. 


\subsection{Procedimentos para coleta de dados}

O estudo foi realizado em três etapas:

\subsubsection{Pré-teste: aplicação do Inventário Portage Operacionalizado}

Foi focalizada nesse estudo a área de desenvolvimento motor para a faixa etária anterior a de três a quatro anos até que o aluno adquira estabilidade de acertos nos escores do inventário. De acordo com o procedimento, se identificar que o desempenho do aluno está insuficiente retrocede-se a faixa etária. Para parar o retrocesso o aluno deverá ter pelo menos 15 acertos consecutivos. Será importante iniciar as sessões com atividades agradáveis aos alunos (jogos e brincadeiras) (WILLIAMS; AIELLO, 2001)

\subsubsection{INTERVENÇÓES NECESSÁRIAS DE ACORDO COM AS NECESSIDADES APRESENTADAS NO PRÉ-TESTE}

Foram desenvolvidas atividades a partir da análise obtida pelo aluno nos itens do Inventário Portage. As intervençóes foram realizadas de acordo com as necessidades apresentadas pelo aluno. Todas as intervençóes foram realizadas no ambiente escolar, na sala regular. $\mathrm{O}$ aluno não foi privado das atividades de rotina da sala de aula e foi utilizado o mesmo conteúdo programático das aulas no momento da intervenção. Nessa etapa as atividades propostas foram:

I) Brincadeiras, atividades com bola para desenvolver o comportamento de atirar e arremessar e espera-se com a intervenção chutar uma bola que está imóvel, atirar e arremessar a bola.

II) Deslocamento entre as atividades: andar de costas, na ponta dos pés, andar com um pé na frente do outro e espera-se andar de costas, na ponta dos pés, andar com um pé na frente do outro.

III) Atividades em sala de aula: rasgar papel, desenhar com giz de cera em uma folha em branco, pintar com tinta utilizando somente as máos como riscadores, brincar com massinha e dobrar papéis. Espera-se: segurar lápis e giz com o polegar e o indicador, fazer bolas com massinha e dobrar papéis.

IV) Hora da história: Atividade na biblioteca para ouvir histórias e manusear livros e espera-se manusear livros e virar páginas.

V) Hora do parque: atividades livres de acordo com o interesse das crianças e espera-se saltar no mesmo local com os dois pés, andar de costas, descer escadas sem ajuda.

VI) Apoio dos jogos de montar: encaixar as partes dos brinquedos e desencaixar, montar formas e desmontar formas e espera-se construir uma torre de cinco blocos, desmanchar e construir brinquedos de encaixe por pressão.

\subsubsection{Pós-TESTE}

Foi aplicado o inventário Portage Operacionalizado novamente para avaliar o avanço no desenvolvimento do participante da pesquisa. 


\subsection{Procedimento para ANÁlise de dados}

Os dados obtidos no pré-teste foram descritos e comparados com os dados obtidos no pós-teste. Os dados obtidos durante a intervenção serão descritivos e terão origem no diário de campo.

Espera-se com os resultados obtidos contribuições para a escolarização mais efetiva da criança com SD na Educação Infantil.

\subsection{Procedimentos éticos}

O projeto de pesquisa foi submetido ao Comitê de Ética em pesquisa com seres humanos da Plataforma Brasil com o parecer número 368.534.

\section{Resultados E Discussóes}

A apresentação, análise e discussão dos resultados serão realizadas simultaneamente com base no Referencial Curricular Nacional para a Educação Infantil (RCNEI) (BRASIL, 1998). Os dados coletados foram descritos, discutidos e analisados.

\subsection{Pré - teste}

Com base no planejamento curricular proposto por Willians e Aiello (2001) sobre o que ensinar para crianças e como proceder com tais procedimentos os comportamentos relativos ao desenvolvimento motor foram levantados. Para estabelecer a faixa etária do aluno em relação ao desenvolvimento motor foram feitas até cinco tentativas até ocorrer constância nos resultados.

\subsubsection{Desenvolvimento Motor}

Conforme orientação do Inventário Portage (WILLIANS; AIELLO, 2001), a área do desenvolvimento motor foi a primeira trabalhada. Como o participante tem entre três e quatro anos, retrocederam-se as faixas-etárias até ocorrer acertos nos itens do inventário. No primeiro momento retrocedeu-se para a faixa de dois a três anos. Os dados a seguir mostram o resultado do pré-teste.

O aluno participante se encontra, de acordo com o Inventário, na faixa etária de um a dois anos computando 36\% de erro em relação aos comportamentos relacionados à faixa etária.

O pré-teste para a faixa etária de um a dois anos foi realizado na semana seguinte a identificação da necessidade do retrocesso (da faixa etária de dois a três anos) para identificar o nível de desenvolvimento motor do participante.

$\mathrm{O}$ primeiro item (46) sobe escadas engatinhando o participante não realizou em nenhuma das tentativas.

Nos itens 47, 48 e 49, coloca-se em pé, estando sentado, rola uma bola imitando um adulto e sobe em uma cadeira de adulto, vira-se e senta-se. $\mathrm{O}$ participante obteve êxito em $100 \%$ das tentativas. 
No item 50, colocar quatro aros em uma pequena estaca, no 52 , encaixa pinos de 2,5 cm em uma prancha de encaixe, no 53, constrói uma torre de três blocos, no 56, desce escadas sentado, colocando primeiro os pés e no 62, dobra o corpo, sem cair, para apanhar objetos no chão. $\mathrm{O}$ participante não acertou em nenhuma tentativa.

Por fim, nos itens 57, 58, 59, 60, 61 e 63 que equivalem aos comportamentos: senta-se em uma cadeirinha, agacha-se e volta a ficar em pé, empurra e puxa brinquedos ao andar, usa cadeira ou cavalo de balanço, sobe escadas com ajuda e imita um movimento circular (WILLIANS; AIELLO, 2001), o participante acertou todas as tentativas.

\subsection{INTERVENÇÁO}

\subsubsection{BRINCADEIRAS}

As atividades na Educação Infantil possuem caráter lúdico que engloba jogos e brincadeiras para promover aprendizagem aos alunos. Essa característica é o elemento propulsor dos métodos e dos mecanismos de desenvolvimento das crianças. O brincar auxilia no desenvolvimento da imaginação. A criança não brinca porque imagina, mas imagina porque brinca. Com base no RCNEI (BRASIL, 1998) "[...] ao brincar as crianças buscam imitar, imaginar, representar e comunicar de forma específica [...] brincar é um momento que se pode observar a coordenação das experiências prévias das crianças" (p.22)

Ao intervir através de brincadeiras a criança tem possível potencial de desenvolvimento tanto intelectual como motor. Santos, Weiss e Almeida (2010) reforçam em seu estudo a relevância de programas de intervenção para essa população salientando que as crianças SD possuem déficit motor e que intervençóes voltadas para essa área mostram avanços positivos em organização espacial, equilíbrio e motricidade global.

A rotina da educação infantil precisa estar organizada para contemplar momentos que valorizam as brincadeiras e a ludicidade através da mediação pedagógica. Diante disso, a pesquisa de Santos, Weiss e Almeida (2010) ao trabalhar com uma criança SD apontam que "[...] utilizar a fantasia com essas crianças facilita a vivência dos exercícios, assim como amplia a percepção de mundo estimulando o desenvolvimento do pensamento integrando-os aos aspectos afetivo-motores" (p.28). O estudo apresentado pelos pesquisadores ressalta a importância da estimulação com atividades lúdicas e que esse fator possibilita que a criança SD atinja níveis satisfatórios em relação ao desenvolvimento motor.

As atividades descritas a seguir tiveram como objetivo promover situaçóes em que a criança com SD pudesse se desenvolver dentro do contexto coletivo que o ambiente escolar proporciona. No estudo de Boccardi (2003) ao propor um programa de intervenção motora lúdica inclusiva para identificar, descrever e analisar o nível de desenvolvimento motor de crianças com SD, deficiência mental, síndrome de X-frágil e criança típica salienta que o brincar foi um recurso para minimizar a resistência a inclusão. Outro ponto importante identificado mostra o brincar como elemento que satisfaz as necessidades infantis.

O lúdico foi amplamente trabalhado no presente estudo. Todas as atividades foram desenvolvidas em ambiente escolar e coletivo. Os recursos utilizados foram retirados do cotidiano escolar e familiar para dar significado real ao aluno participante. 
Nesses momentos foram valorizadas atividades lúdicas com bola no coletivo e em pares para desenvolver o comportamento de atirar e arremessar bolas conforme previsto no Inventário Portage (WILLIANS; AIELLO, 2001). O aluno apresentou avanços em relação aos comportamentos de atirar uma bola e chutar uma bola grande e imóvel. Os dados coletados em relação às atividades lúdicas proporcionaram melhorias no desenvolvimento motor bem como apresentados, também, nos estudos de Boccardi (2003).

\subsubsection{Deslocamento entre as ATIVIDADES}

Entre uma atividade e outra os alunos, juntamente com a professora, precisavam se locomover entre os ambientes da escola. Para contemplar esse momento a turma do aluno com SD foi organizado o deslocamento para andar em pares e trios para acompanhar náo só o ritmo do aluno com SD como também dos demais alunos. Nesses momentos a professora sempre solicitava aos alunos determinada tarefa, como: andar de costas, na ponta dos pés, andar com um pé na frente do outro. Com essas atividades o aluno conseguiu apenas andar de costas em um período de seu interesse. Importante salientar que tais atividades eram acompanhadas com músicas diversas cantadas pelos alunos e pela professora. Nessas atividades foram contempladas as áreas de música e movimento (BRASIL, 1998). Na educação infantil um dos objetivos para a área do movimento na faixa etária do aluno com SD é descolar-se com destreza ao andar, correr, pular e assim desenvolver confiança em suas capacidades motoras. As atividades propostas visaram oportunizar ao aluno momentos em que ele pudesse desenvolver seu potencial do movimento para adquirir autonomia e independência nas atividades escolares. Em música trabalha-se na educação infantil o momento lúdico ao imitar, inventar e reproduzir criaçóes músicas para crianças com três anos (BRASIL 1998). Conforme estudos já apresentados (SANTOS; WEISS; ALMEIDA, 2010) no presente trabalho o lúdico é fator importante para o desenvolvimento motor, bem como programas de intervenção.

Smeha e Semiotti (2008) ao propor um estudo sobre relaçóes interpessoais entre colegas de classe de crianças com SD destacam que a intervenção do professor é “[...] determinante para aceitação, rechaço ou indiferença ao comportamento dos colegas” (p.81). Na presente pesquisa a mediação da professora favorecer o desenvolvimento das atividades de deslocamento com intervenção e intenção de manter o grupo unido e desenvolver as habilidades não só motoras como também os conteúdos pertinentes à faixa etária e ao RCNEI (BRASIL, 1998).

\subsubsection{ATIVIDAdes em SALA DE AUla}

Em sala de aula as atividades realizadas tinham como material o caderno, folhas diversas, giz de cera, lápis de cor, tintas, pincéis e cola.

Atividades como rasgar papel, desenhar com giz de cera em uma folha em branco, pintar com tinta utilizando somente as mãos como riscadores e dobrar papéis, foram desenvolvidos para ensinar comportamentos como segurar lápis e giz com o polegar e o indicador e dobrar papéis. Dentre esses comportamentos o RCNEI (BRASIL, 1998) propóe na área do movimento, "[...] explorar e utilizar os movimentos de preensão, encaixe e lançamento para objetos diversos” (p.27). Tais características também podem ser encontradas no Inventário Portage (WILLIANS; AIELLO, 2001). O aluno apresentou instabilidade ao segurar os riscado- 
res, ora com a mão direita ora com a mão esquerda. Ora segurando com o polegar e o indicador ora com o movimento de preensão. Entretanto chegou a segurar de forma convencional. Em relação a dobrar papéis conseguiu dobrar seguindo o modelo apresentado pela professora.

Como o aluno possuía comportamentos inadequados, por exemplo, jogar o material e as folhas de atividades em qualquer local, foram criados recursos para fixar as folhas à mesa com fita adesiva. Para diminuir o comportamento de ficar andando pela sala, outra estratégia utilizada para diminuir esse comportamento foi utilizar-se de recursos tecnológicos (DVD e televisão). A professora passava vídeos curtos no início da aula e depois no final da aula. Os vídeos escolhidos eram sempre de interesse prévio do aluno. Brito et al. (2009) utilizando o Inventário Portage (WILLIANS; AIELLO, 2001) como instrumento ao avaliar o perfil cinestésico-corporal de crianças com SD apresentam que as crianças possuem dificuldade em realizar tarefas de coordenação motora fina. Outro dado importante apresentado no estudo se refere à hipotonia periférica ou central apresentada, associada ao déficit da coordenação motora fina.

No presente estudo o aluno apresentou instabilidade ao manter a coordenação motora fina ao segurar instrumentos como riscadores, fato esse também apresentado no estudo de Brito et al. (2009) e relaciona-se também a hipotonia. Entretanto ao utilizar as mãos como riscadores em atividades com tinta o aluno não apresentou dificuldade. Para essa atividade foi disponibilizado ao aluno uma folha de papel A3 e tinta à vontade.

\subsubsection{HORA DA HISTÓRIA}

Tais atividades foram realizadas na biblioteca da escola. Nesse momento a professora disponibilizava aos alunos livros para manusear após a história. Ao aluno com SD eram disponibilizados sempre os mesmos livros. O contato direto com os livros proporcionou ao aluno momentos de aumentar seu repertório e desenvolver o interesse por histórias. Além de desenvolver o comportamento de virar páginas de livros. Além de estabelecer constância no comportamento de virar páginas de livros as atividades desenvolvidas proporcionaram a oportunidades de trabalhar as áreas de linguagem oral e escrita além de novamente atingir objetivos da área de movimento do RCNEI (BRASIL, 1998). O estudo de Anunciação (2013) relata a importância das histórias em momentos lúdicos nos processos de escolarização de uma criança com deficiência na educação infantil. No momento da hora da história, as atividades organizadas, levaram o aluno a se interagir com o grupo:

[...] as atividades proporcionaram ao aluno situaçóes de interação mediadas com ato intencional. O aluno passou a interagir com as atividades e com o grupo de acordo com suas limitaçóes, porém em nenhum momento essas limitaçôes foram explicitadas. Todas as atividades visaram à promoçáo do aluno em situaçóes de interaçáo que são constantes nos processos educativos. Outro aspecto identificado, as atividades lúdicas auxiliam nas práticas inclusivas, porém a visão da inclusão estava no olhar do professor e não nos alunos (p.8)

A característica apresentada acima identifica um elemento importante no processo de escolarização em que as atividades lúdicas propostas nesse estudo auxiliaram nas práticas inclusivas e que esse aspecto estava presente no olhar apenas do educador e não dos alunos. Esse estudo proporcionou situaçóes de interação entre o aluno e o grupo, mediadas por ação 
intencional do professor para trabalhar situaçôes de aprendizagem significativas para o desenvolvimento do aluno.

A Educação Infantil e suas características lúdicas é uma etapa da escolarização importante para o desenvolvimento não só do aluno com deficiências, mas de todos os alunos sem distinçóes. É através das brincadeiras que as crianças se reconhecem como parte integrante de grupos, testam suas açóes e representam o mundo a sua volta. Com isso, toda pedagogia deve estar centrada na criança valorizando suas potencialidades.

\subsubsection{HORA DO PARQUE}

O parque da escola possui diversos brinquedos e recursos naturais (areia, árvores e plantas) para utilizar no planejamento das aulas.

A intervenção nesse momento valorizou o interesse prévio do aluno por ser um ambiente de atividades livres para as crianças, entretanto sempre com orientação da professora.

O "comportamento de dar cambalhotas para frente com ajuda" não foi desenvolvido, pois de acordo com a literatura a criança com SD pode apresentar instabilidade atlanto-axial, "[...] essa instabilidade pode levar o indivíduo à subluxação atlanto-axial ou à compressão da medula espinhal, resultando em déficit neurológico e até, possivelmente, em morte (GUSMAN; TORRE, 1999, p.169).

Como o parque dispunha de brinquedos com escadas, escorregadores, barras estáticas e balanços a professora orientava o aluno ao brincar nos brinquedos. Por exemplo, saltar com ambos os pés para alcançar as barras estáticas conforme previsto no Inventário Portage (WILLIANS; AIELLO, 2001).

Para subir na escada a professora esperava o aluno em cima do brinquedo e assim que ele subisse cantava uma música de interesse do aluno. Para descer no escorregador era feito o mesmo procedimento. Assim, conforme estudo de Santos, Weiss e Almeida (2010) com crianças SD “[... eleva-se a importância do desenvolvimento motor durante a infância, considerando também que o acompanhamento da aptidão motora de crianças em idade escolar constitui atitude preventiva quanto à aprendizagem" (p.20)

\subsubsection{APOIO DOS JOGOS DE MONTAR}

A escola possui diversos tipos de jogos de montar e encaixe. Nos momentos estipulados no cronograma da semana da professora os jogos eram trabalhados com o aluno SD juntamente com a turma toda. A intervenção direta em encaixar as partes dos brinquedos e desencaixar, montar formas e desmontar formas foi intensamente trabalhada contemplando as áreas de matemática e movimento do RCNEI (BRASIL, 1998). Atividades como construir torres com os blocos foram trabalhadas no coletivo e individualmente. Por exemplo, construção de torres com auxílio de todos os alunos da turma e torres construídas individualmente. A intervenção com o aluno SD necessitou de atenção direta, entretanto ele desenvolvia a atividade através do modelo apresentado. Imitar significar aprender com o outro sendo esse aspecto importante para desenvolver o processo de diferenciação entre o eu e o outro (BRASIL, 1998). Tal aspecto 
proporcionou ao aluno momentos de aprendizagem de acordo com as necessidades para desenvolver os comportamentos relacionados ao Inventário Portage (WILLIANS; AIELLO, 2001).

\subsection{Pós-teste}

O aluno apresentou avanços em relação ao desenvolvimento motor. O Inventário Portage (WILLIANS; AIELLO, 2001) foi aplicado novamente e os resultados demonstram que o aluno SD obteve avanços passando para a faixa etária de dois a três anos com equivalente a 70,5\% dos comportamentos elencados para essa faixa etária. Os comportamentos relacionados à faixa etária de três a quatro anos foram mensurados e o participante obteve $26,6 \%$ de acertos demonstrando que ele ainda precisa avançar nos comportamentos necessários para atingir essa faixa etária.

\section{Conclusónes}

A escolarização do aluno com SD se fez importante para proporcionar ao aluno momentos de desenvolvimento, não só motor como também na socialização com o ambiente escolar. Em nenhum momento o déficit do aluno minimizou sua permanência na escola. Os demais alunos contribuíram a esse processo sem serem solicitados.

No início da pesquisa, no pré-teste o aluno encontrava-se na faixa etária do desenvolvimento motor entre um e dois anos conseguindo atingir ao objetivo de identificar o nível de desenvolvimento motor do aluno com SD no contexto escolar

A intervenção ajudou a melhorar esse nível e avançar para a etapa seguinte. As atividades lúdicas propiciaram momentos de crescimento individual e coletivo de todo o grupo de alunos. Com o objetivo de intervir com estratégias de ensino necessárias para responder às necessidades de seu desenvolvimento as atividades elaboradas pela professora propiciaram situações em que os conteúdos pertinentes à Educação Infantil fossem trabalhados, também visando o desenvolvimento motor, como atividades com bola, massinha, momentos no parque, rasgar papel, desenhar com giz de cera e tinta. $\mathrm{O}$ ambiente lúdico estimulou o avanço a níveis satisfatórios do desenvolvimento motor do aluno com SD.

Após a intervenção, no pós-teste, o aluno com SD alcançou a faixa etária de dois e três anos, ao avaliar os avanços no desenvolvimento motor, porém ainda apresenta as características de hipotonia. A mediação pedagógica contribuiu para o avanço no desenvolvimento do aluno, entretanto se deve considerar seu próprio desenvolvimento natural durante o período em que a pesquisa foi desenvolvida.

A área educacional carece de estudos voltados não só ao desenvolvimento motor como também para o ensino de crianças com síndrome de Down na Educação Infantil. O presente estudo colabora para o avanço de pesquisas na área ao colocar a Educação Infantil como ambiente que favorece ensino e estimulação de alunos com SD sem que ele seja privado do processo de escolarização. 


\section{REFERÊNCIAS}

ANUNCIAÇÃO, L. M. R. L. Escolarização de uma criança com síndrome de Down: um olhar para o Referencial Curricular Nacional. In: ENCONTRO IBERO AMERICANO DE EDUCAÇÃO, 8., 2013, Araraquara. Anais... Araraquara: Unesp, 2013. p.1-8.

BOCCARDI, D. Programa de intervenção motora lúdica inclusiva: análise motora e social de casos específicos de deficiência mental, sindrome do X-frágil, sindrome de Down e criança típica. 2003. $169 \mathrm{f}$. Dissertaçáo (Mestrado em Ciências do movimento humano), Universidade Federal do Rio Grande do Sul, Porto Alegre, 2003.

BRASIL. Constituição da República Federativa do Brasil. Brasília, DF: Senado Federal, 1988.

BRASIL. Senado Federal. Lei de Diretrizes e Bases da Educaşão Nacional. Brasília, DF: Diário Oficial da União, 23 de dezembro. 1996. Lei no 9.394/96 artigo 59, incisos I, IV e V.

BRASIL. MINISTÉRIOS DA EDUCAÇÁO E DO DESPORTO. Referencial Curricular nacional para a educação infantil. Brasília, DF: MEC/SEF, 1998.

BRASIL. Conselho nacional de educação. Resolução n. 2,11 de setembro de 2001. Institui Diretrizes Nacionais para a Educação Especial na Educação Básica. Diário Oficial [da] República Federativa do Brasil, Brasília, DF, Seção 1, n.177, 14 set, 2001.

BRASIL. Ministério da Educação. Secretaria de Educação Básica. Diretrizes curriculares nacionais para a educação infantil / Secretaria de Educação Básica. - Brasília, DF: MEC, SEB, 2010.

BRITO, A. et al. Avaliação do perfil cinestésico-corporal de crianças com Síndrome de Down: um parâmetro para se atender à proposta das Diretrizes Curriculares Nacionais para a Educaçáo Especial. Ensaio: aval. pol. públ. Educ., Rio de Janeiro, v.17, n.63, p.341-354, 2009.

CAMPOS, A. C.; COELHO, M. C.; ROCHA, N. A. C. F. Desempenho motor e sensorial de lactentes com e sem síndrome de Down: estudo piloto. Fisioterapia e Pesquisa, São Paulo, v.17, n.3, p.203-208, 2010.

CARVALHO, R. E. Educação inclusiva: com os pingos nos “is". Porto Alegre: Mediação, 2010.

COMIN, B. C. Ativitades estimuladoras de leitura e escrita em estudantes com sindrome de down. 2013. Dissertação (Mestrado em Educação Especial), Universidade Federal de São Carlos, São Carlos, 2013.

CORRÊA, J. C. F. et al. A existência de alteraçóes neurofisiológicas pode influenciar na compreensão do papel da hipotonia no desenvolvimento motor dos indivíduos com síndrome de Down. Fisioterapia e Pesquisa, São Paulo, v.18, n.4, p.377-38, 2011.

FARIA, M. N. M. Alfabetização de crianças portadoras de sindrome de down: analisando uma proposta de ensino. 1993. Dissertação (Mestrado em Educação Especial), Universidade Federal de São Carlos, São Carlos, 1993.

FONSECA, K. A. Análise de adequaçöes curriculares no ensino fundamental: subsídios para programas de pesquisa colaborativa na formaçâo de professores. 2011. 125f. Dissertação (Mestrado em Psicologia do desenvolvimento e aprendizagem), Universidade Estadual Paulista, Bauru, 2011.

GUSMAN, S. TORRE, C. A. Fisioterapia na síndrome de Down. In: SCHWARTZMAN, J. S. (Org.). Sindrome de Down. São Paulo: Mackenzie: Memnon, 1999. p.167-205.

LAMORÉA, M. L. O ensino de portadores da sindrome de down através do método montessori: análise de desempenho de três crianças em relaçáo a seis atividades. 1995. Dissertação (Mestrado em Educaçáo Especial), Universidade Federal de São Carlos, São Carlos, 1995. 
LEME, L. M. R. Informática como recurso pedagógico para a prática de uma professora de Educação Especial. 2010. 138f. Dissertação (Mestrado em Educação Especial), Universidade Federal de São Carlos, São Carlos, 2010.

ROSA E LUIZ, F. M. et al. A inclusão da criança com síndrome de down na rede regular de ensino: desafios e possibilidades. Revista Brasileira de Educação Especial, Marília, v.14, n.3, p.497-508, 2008.

PERRENOUD, P. Pedagogia diferenciada: das intençôes à ação. Porto Alegre: Artmed, 2000.

SANTOS, A. P. M.; WEISS, S. L. I.; ALMEIDA, G. M. F. Avaliação e intervenção no desenvolvimento motor de uma criança com Síndrome de Down. Revista Brasileira de Educaçáo Especial, Marília, v.16, n.1, p.19-30, 2010.

SERÉS, A. et al. Sindrome de Down de A-Z. Campinas: Saberes Editora, 2011.

SILVA, D. R.; FERREIRA, J. S. Intervençôes na Educação Física em crianças com síndrome de Down. Revista de Educação Física/UEM, Maringá, v.12, n.1, p.69-76, 2001.

SMEHA, L. N.; SEMIOTTI, N. Inclusão e síndrome de Down: um estudo das relaçóes interpessoais entre colegas de escola. Psicologia Argumento, Curitiba, v.26, n.52, p.73-83, 2008.

TEIXEIRA, F. C.; KUBO, O. M. Características das interaçôes entre alunos com síndrome de down e seus colegas de uma turma no sistema regular de ensino. Revista Brasileira de Educação Especial, Marília, v.14, n.1, p.75-92, 2008.

UNESCO. Declaração de Salamanca e linha de ação sobre necessidades educativas especiais. Brasília, DF: CORDE, 1994.

VILELAS, J. Investigação: o processo de construção do conhecimento. Lisboa: Edições Silabo, 2009.

WILLIAMS, L. C. A.; AIELlO, A. L. R. O inventário Portage operacionalizado: intervenção com famílias. São Paulo: Memnon, 2001.

YIN, R. Estudo de caso: planejamento e métodos. 2.ed. Porto Alegre: BOOKMAN, 2001.

Recebido em: 27/03/2014

Reformulado em: 25/03/2015

Aprovado em: 25/04/2015 
ANUNCIAÇÃO, L.M.R.L.; COSTA. M.P.R; DENARI,. F.E. 